\title{
EL FACTORING EN LA LEGISLACIÓN CHILENA
}

Norma Nuñez Ojeda

\section{Roxana Venegas Díaz}

El presente artículo contiene un resumen de nuestra tesis de investigación, presentada en octubre del 2000 en la Escuela de Derecho de la Universidad Católica del Norte, Sede Coquimbo, para optar al grado de licenciadas en Ciencias Jurídicas.

La Investigación fue elaborada bajo la dirección del profesor de Derecho Tributario, señor Luis Gastón Yver Hudson, siendo profesor informante de ella, el señor Tomás Menchaca Olivares ${ }^{1}$.

\section{I.- Estructura²}

Este estudio está dedicado al análisis del origen, desarrollo, características, importancia y aplicación práctica. De lo que significa la incorporación a nuestra realidad económica, a comienzo de la década de los noventa, de una nueva figura atípica denominada "Factoring", la que, $\sin$ duda, escapa a nuestros moldes tradicionales.

En ella se realiza un exhaustivo análisis, abordándolo desde un punto de vista jurídico, más que económico. Su estudio es algo complejo, más aún, cuando sabemos que carece de una regulación propia por parte de nuestro ordenamiento positivo y de aclaraciones de importancia por parte de la doctrina nacional.

Lo anterior, no representa una crítica, sino más bien, precisar que, aunque ella tiene una aplicación práctica en nuestra realidad, existen situaciones que deben ser abordadas y aclaradas por nuestros legisladores.

Este Estudio está conformado por un índice, cinco capítulos y conclusiones finales.

En su introducción se hace referencia al nacimiento y adecuación de esta figura atípica, a la realidad jurídico-económica mundial, destacándose lo que acontece con ella en la práctica chilena.

\footnotetext{
${ }^{1}$ Profesor de Derecho Económico de la Escuela de Derecho de la Universidad Católica del Norte.

${ }^{2}$ Este trabajo está basado en publicaciones de autores tanto extranjeros como nacionales.
} 
Sobre la base de estos estudios, se desarrolla también la falta de regulación que el "Factoring" ha tenido por parte de nuestro ordenamiento jurídico, pretendiendo con este trabajo escrito colmar una importante laguna que existe en relación a él.

Otro de los aspectos tratados, debido a su importancia y haciendo referencia a la asimilación que nuestro derecho ha efectuado en relación al "Factoring", es el estudio de la nueva legislación bancaria, que recepciona expresamente esta figura a fines del año 1997 y la contempla como una alternativa más para realizarla por instituciones bancarias, lo que viene a llenar un vacío legal que desde los inicios del "Factoring" en nuestro país, no se había podido soslayar.

En el Capítulo I, "Parte General ", se desarrollan las nociones generales relativas al origen y evolución del "Factoring".

El Capítulo II, denominado "Análisis Jurídico del Factoring", está dedicado al estudio del concepto y descripción de él, incluyendo el análisis de su naturaleza y estructura jurídica, derechos y obligaciones; y por último, sus clasificaciones según los distintos aspectos, tales como: cesión del riesgo, servicio prestado, ámbito geográfico, etcétera.

El Capítulo III, "El Factoring en Chile", ha sido dividido en dos párrafos, el primero denominado "Idea Preliminar", y el segundo "Historia de su Introducción en Chile".

En el Capítulo IV, denominado "Aspectos Tributarios del Factoring", se desarrolla el estudio desde el punto de vista tributario, abarcando el tema de la Factura, y los diversos impuestos a que ésta nueva figura atípica pueda estar afecto.

El Capítulo V, "El Factoring en el Mercado Internacional", analiza la figura en estudio, en relación a su origen y evolución mundial, conjuntamente con las ventajas que él representa en el desarrollo de la actividad de exportación como de importación. Se incluye también en este capítulo, un análisis de la Convención de UNIDROIT sobre "Factoring" Internacional.

Como última parte de este estudio, las Conclusiones Finales, en las cuales se exponen razonamientos personales, enfocados desde dos puntos de vista, uno jurídico, tema principal de este trabajo, y otro económico.

\section{II.- "El Factoring, en la Legislación Chilena y reflexiones personales".}

En primer lugar, debemos decir que el "Factoring", tiene un origen anglosajón, pero es en Norteamérica donde adquiere las características propias del "Factoring" actual, y que se ha sido poco a poco incorporando a nuestro medio. 
Cuando hablamos de él, estamos haciendo referencia a un conjunto de actos jurídicos bilaterales ${ }^{3}$, que como tal, no se encuentran regulados expresamente por la ley, es decir, se caracterizan por ser atípicos. Estos actos, se celebran entre la empresa de "Factoring" y el Cliente, en virtud del cual, el segundo, se obliga a efectuar una mera entrega o bien, a transferir en dominio, al primero, los créditos presentes $\mathrm{y} / \mathrm{o}$ futuros que nazcan de su actividad empresarial y que sean previamente aprobados por el Factor; por su parte, el Factor, se obliga a prestar un conjunto de servicios, ya sea de carácter financiero, gestión y/o garantía al segundo, según lo pactado, cobrando por la prestación de ellos, una comisión variable, a la cual deberá sumarse la tasa de interés respectiva, cuando dentro de los servicios pactados encontremos el de financiamiento, teniendo todo ello como finalidad la colaboración empresarial.

De esta manera, aparece una alternativa real para las empresas, principalmente las PYME, pues, entre los servicios que presta la empresa de "Factoring", se encuentra el anticipo de fondos con cargo a los créditos que los empresarios tienen contra sus clientes, lo que otorga a las empresas mayor autonomía financiera, evitando de este modo el endeudamiento en que incurrirían en el evento de no existir esta figura.

Ahora bien, frente a la pregunta ¿Cuál es la naturaleza jurídica del "Factoring"? debemos aclarar desde ya, que él no constituye un "contrato", es decir, no lo enmarcamos dentro de los actos jurídicos bilaterales que tienen por objeto crear obligaciones, toda vez que dicha expresión, fue ideada bajo otra realidad y que, por lo mismo, no cubre adecuadamente esta nueva forma de negociación, pues, él se caracteriza principalmente por constituir un complejo articulado de servicios en el que destacan tres funciones básicas, denominadas gestión o prestación de servicios, garantía o asunción de riesgo y financiamiento, constituyéndose de esta forma, en una figura compleja.

En virtud de lo anterior, afirmamos que él, no sólo está compuesto de un acto, sino que por un conjunto de ellos, los cuales no sólo están destinados a crear derechos y obligaciones, sino también a modificar o a extinguirlos, razón por la cual denominarlo "contrato", significaría limitar los términos de esta figura.

Por otro lado, no se participa de la denominación "operación", como lo hace parte de la doctrina, tanto nacional como internacional, encontrándose entre ellos los autores Ricardo Sandoval ${ }^{4}$ y Juan Farina ${ }^{5}$, por ser éste, un concepto propio de la economía, y por ende, al margen del ámbito jurídico.

\footnotetext{
${ }^{3}$ A diferencia de la opinión mayoritaria de la doctrina que lo considera como un "contrato".

${ }^{4}$ SANDOVAL Ricardo "Nuevas Operaciones Mercantiles" Editorial ConoSur Ltda, 1996. Pág.66.
} 
En cuanto a su existencia, es necesario la concurrencia de dos presupuestos. En primer término, debe estar presente el presupuesto básico de esta figura, que está constituido por la actividad comercial desarrollada por el cliente, en virtud de la cual nacen los créditos que serán objeto de él. Dicha actividad debe ser de aquellas en la cual, el cliente conceda a sus compradores un plazo para el pago, permitiendo de este modo generarse de una cantidad significativa de créditos, para que se justifique recurrir a esta nueva figura.

En segundo lugar, es necesario la existencia de un presupuesto esencial, que lo constituye la mera entrega del documento en que consta el crédito, cuando se trate de créditos presentes $y$, tratándose de créditos futuros, lo constituirá la obligación por parte del cliente de entregar dichos créditos cuando ellos nazcan, sin que sea esencial en ambos casos la intención de transferir por parte del cliente, ni de adquirir por parte del factor del dominio de ellos.

Además de la existencia de dichos presupuestos, es necesario la intervención de tres partes, de las cuales, dos de ellas tienen el carácter de directas, mientras que la restante es considerada como indirecta. Dentro de las primeras, encontramos al Factor y Cliente, vinculados a una estructura de funcionamiento jurídico peculiar. Como parte indirecta, encontramos los deudores del Cliente, quienes deben vincularse con el Factor mediante una notificación ${ }^{6}$ que será judicial cuando el crédito es civil, o bien efectuada por un ministro de fe cuando el crédito es mercantil, notificación que de acuerdo a nuestro Código Civil, queda bajo la responsabilidad del cesionario de los créditos, que en este caso en particular, corresponde al Factor, salvo acuerdo contrario de las partes $^{7}$.

En cuanto a finalidades que pueden llevar a las partes a celebrarlo, son la prestación de tres servicios básicos, que consisten en: Gestión y/o Garantía y/o Financiamiento, los que pueden estar presentes conjunta o independientemente, sin que ello altere su carácter de tal ("Factoring"), siendo únicamente esencial a él, el servicio de gestión, pues es el único del cual no puede prescindirse.

El servicio de gestión contempla la entrega de información por parte de la empresa de "Factoring" al cliente, tales como: referencias a la situación financiera,

\footnotetext{
${ }^{5}$ FARINA Juan. Contratos Comerciales Modernos. Editorial Astrea de Alfredo y Ricardo Depalma. Buenos Aires. 1994. Pág.522.

${ }^{6}$ La finalidad de esta notificación, es la de poner en conocimiento del deudor la cesión o mera entrega de un documento en que constan los créditos y siempre que éstos tengan el carácter de nominativos.

${ }^{7}$ En relación a los créditos a la orden y al portador, que son obieto do factorización ellos quedan regulados por la normativa contemplada en el Código de Comarcio en sus artículos 162 y siguientes.
} 
comercial, empresarial, entre otras; la realización de gestiones que dicen relación con el cobro de los créditos, ya sea en su fase prejudicial como en la judicial ${ }^{8}$.

En cuanto al servicio de garantía, tiene lugar cuando la cesión de créditos que opera en virtud de la transferencia que se realiza entre cliente y factor adquiere la modalidad pro soluto, es decir, cuando el factor asume el riesgo de no pago por insolvencia del deudor. En la practica chilena el factor no asume tal riesgo, teniendo por tanto, la transferencia, un carácter pro solvendo ${ }^{9}$, no existiendo de esta manera el servicio de garantía.

Por último, en relación al servicio de financiamiento y, aun cuando éste se presta usualmente por el Factor y sea el responsable del gran desarrollo del "Factoring", no es esencial a él, pero de pactarse, puede ser prestado de dos formas:

- Un financiamiento del $100 \%$ del valor del documento que fue objeto de la cesión que ha operado previamente. Este pago se realiza al momento del vencimiento de dicho documento y sólo si el deudor lo ha pagado; o bien:

- Mediante anticipo del $80 \%$ del valor del documento, mientras que el saldo, se pagará una vez que se verifique el pago por el deudor.

En la práctica, para la materialización de este último servicio, es necesario que el factor efectúe previamente la aprobación de los créditos, la cual no siempre se realiza de manera singular para cada uno de ellos, sino, que la mayoría de las veces, lo hará mediante la aprobación de un fondo de crédito por cada deudor habitual del cliente.

En cuanto a los documentos que contienen los créditos que serán objeto de factorización, encontramos no sólo la factura, como lo fue en un principio y, como lógicamente podría pensarse y principalmente producto del incremento de las relaciones comerciales entre los distintos agentes económicos, su ámbito de aplicación se extiende también a otros documentos, tales como, letra de cambio, cheque, pagaré, y otros. No obstante lo anterior, la factura sigue siendo el documento que con mayor frecuencia es objeto de él, ello porque la empresa Cliente generalmente documentará las transacciones que dan origen a los créditos a través de la emisión de facturas.

Por ser la factura, el documento que con mayor frecuencia es objeto de factorización, debemos aclarar, en relación a ella, si puede o no ser considerada un

\footnotetext{
${ }^{8}$ Ello tendrá lugar cuando el cobro por parte de la empresa de "Factoring" por la vía prejudicial no haya dado resultados positivos.

${ }^{9}$ Pro solvendo. Modalidad de "Factoring", en la cual la empresa de Factorización no asume el riesgo de insolvencia de los deudores de sus clientes; de ésta manera esta modalidad se opone a la pro soluto, en la cual la empresa asume dicha responsabilidad.
} 
título de crédito y se concluye que no lo es, por carecer de una de las características esenciales de ellos, cual es la autonomía, si el Factor adquiere una factura que proviene de un contrato que finalmente resulta nulo o que por cualquiera otra causa legal no se puede exigir su cumplimiento, éste no podrá exigir al deudor el cumplimiento de la obligación, ya que ella seguirá la misma suerte del contrato que la originó, es decir, el Factor, en este caso, no adquiere el documento con independencia de las relaciones jurídicas anteriores, que es la peculiaridad que presentan todos los títulos de crédito.

Una forma de soslayar la situación en que se encuentra este instrumento, sería mediante la creación de una legislación que le otorgue un carácter distinto del que actualmente tiene, de hecho, han existido iniciativas en el sentido de dotar a la factura de un régimen adecuado, pero que hasta la fecha no han prosperado. De lo anterior, se deduce que es necesario que en nuestro país se revise el tratamiento que actualmente se le da a la factura y se modifique en el sentido de dotarla de mayor eficacia, proporcionándole un carácter que permita al titular de los derechos que ella contiene, efectuar è coobro de lōs señâlados derechos de un modo más rápido y eficienté, sin tener que recurrir, como es en la actualidad, a un largo juicio para que se le declare el carácter de título ejecutivo y de este modo poder dar inicio a un juicio ejecutivo que le permita obtener el cobro de sus derechos.

Respecto a la cesión de créditos que opera en la factorización, se precisa que no parece razonable aceptar la opinión mayoritaria de la doctrina, tanto nacional como internacional, pues, la "cesión de créditos", no constituye, como ellos lo afirman, el presupuesto jurídico esencial del "Factoring", debido a que en algunos casos (gestión de créditos), dicha cesión no se encuentra presente, existiendo solamente una mera entrega de los documentos en que constan los créditos, sin que se encuentre presente en dicha entrega el animo de transferir, por una parte, ni de adquirir por otra el dominio de los créditos, elemento subjetivo esencial para estar en presencia de una cesión de créditos.

Dentro de esta cesión o entrega, según sea el caso y, en relación a la cláusula en virtud de la cual el Cliente se obliga a transferir todos los créditos presentes y/o futuros que nazcan de su actividad empresarial, y analizándola a la luz de nuestro ordenamiento jurídico, se colige que ella es perfectamente válida, pues nuestro Código Civil la permite expresamente en su artículo 1.811, y por otro lado, permite también la venta de cosa futura en su artículo 1.813.

Por lo anteriormente expuesto, se concluye que el presupuesto jurídico esencial del "Factoring", y como se expresó anteriormente, lo constituye la "mera entrega de los documentos en que constan los créditos"; y que tratándose del servicio de garantía y financiamiento, esta mera entrega deberá ir acompañada de la cesión de ellos. 
En cuanto al análisis desde el punto de vista tributario, es decir, los impuestos a que está afecto la mera entrega o cesión de créditos según sea el caso, se debe hacer referencia a tres clases de impuestos; el impuesto a la renta, el impuesto al valor agregado y por último, el impuesto de timbres y estampillas.

En cuanto al impuesto a la renta, se distingue previamente si la empresa de factorización anticipa o no el valor de los créditos cedidos por el Cliente. En el primer supuesto, es decir, cuando se produce el anticipo, la empresa de "Factoring", se encontrará gravada con dicho impuesto, pues, queda comprendida dentro del artículo 20 № 3 del Decreto Ley № 824, sobre el Impuesto a la Renta, por tratarse de una actividad análoga a la realizada por una empresa financiera.

En el segundo supuesto, no se puede aplicar este impuesto, pues ellas no queda comprendida en ninguno de los numerandos del artículo 20 del Decreto Ley, antes mencionado.

Por otro lado y, respecto al impuesto al valor agregado, se distingue el servicio pactado, para determinar si es posible o no la aplicación de él.

Respecto al servicio de gestión, no puede ser gravado con dicho impuesto, al no quedar comprendido dentro del hecho gravado venta, ni del hecho gravado especial contemplado en el artículo 8 del Decreto Ley № 825 . Lo mismo ocurre respecto del servicio de garantía.

En relación al servicio de financiamiento, se colige que si bien se le considera como venta, ella no queda comprendida dentro del hecho gravado por el D.L № 825 , conclusión, a la que también se ha llegado en relación al servicio de garantía, como se explicó en su oportunidad.

En cuanto al impuesto de timbres y estampillas, se distingue, para efectos de determinar su aplicación, si nos encontramos frente a una cesión de créditos o a una mera entrega de ellos en comisión de cobranza.

En el primer caso, es decir, cuando ha operado la cesión de créditos, se concluye, que la aplicación de este impuesto, sólo es posible, en el evento que el Factor adelante el valor del crédito antes de su vencimiento, deduciendo la tasa de interés correspondiente. Ello siempre que cumpla con determinados requisitos, porque esta situación se asemeja al descuento de documentos, que es gravada con el impuesto de timbres y estampillas, cuando se trata de documentos que contengan operaciones de crédito de dinero, y siempre que los documentos en que se da cuenta de la realización de una operación de esta naturaleza, sean emitidos y tengan constancia de haber sido suscritos por las dos partes que interviene en la operación. 
En el segundo caso, es decir, cuando los documentos se entreguen al Factor en comisión de cobranza, sólo quedarán gravados con el presente impuesto, en el evento que el mandatario o comisionista sea una institución bancaria o financiera, ello en virtud de lo dispuesto en el artículo 1 inciso tercero № 3 del Decreto Ley № 3.475, sobre Impuesto de Timbres y Estampillas.

Por último, y desde una perspectiva económica, se visualiza al "Factoring", como una nueva alternativa frente al financiamiento tradicional, evitando el endeudamiento de los empresarios, pues estos lo logran sobre la base de recursos propios, ya que mediante el financiamiento otorgado por el Factor, sus cuentas por cobrar se transforman en liquidez inmediata.

Recapitulando lo expuesto y a modo de conclusión, no debe olvidarse que la actual tendencia a la globalización de los mercados y de las economías, harán aumentar aún más estas cifras, lo que sin duda, se traducirá en una necesidad creciente de capital de trabajo y de los servicios anexos, en los que el "Factoring", aparece como la figura más ventajosa y completa para dar solución a estas necesidades. 